\title{
IgD Myeloma: Dialysis-Independence following High-Dose Melphalan and Autologous Stem Cell Transplantation
}

\author{
Fergal McGlynn $^{\mathrm{a}}$ Siobhan Glavey ${ }^{\mathrm{a}}$ Jeremy Sargent ${ }^{\mathrm{a}}$ Patrick Thornton ${ }^{\mathrm{a}}$ Peter Conlon ${ }^{\mathrm{b}}$ \\ Philip Murphy $^{\mathrm{a}}$ John Quinn ${ }^{\mathrm{a}}$ \\ ${ }^{a}$ Department of Haematology, Beaumont Hospital, Dublin, Ireland; ${ }^{\circ}$ Department of Nephrology, Beaumont Hospital, \\ Dublin, Ireland
}

\section{Dear Editor,}

We read with great interest the report by Kang et al. [1] where they document the outcomes of 22 patients with IgD multiple myeloma (MM) treated with high-dose melphalan and autologous stem cell transplantation (ASCT). In particular, they report improved overall survival (OS) in 10 of 22 patients who received novel agentbased induction therapy followed by ASCT when compared with 12 of 22 who received non-novel agent-based induction. IgD $\mathrm{MM}$ is a rare MM subgroup associated with an aggressive disease course and reduced OS. Here, we report the case of a young woman with IgD MM who presented with dialysis-dependent (DD) renal impairment, was treated with bortezomib-based induction therapy followed by ASCT, and achieved dialysis independence (DI) following ASCT [2].

A 45-year-old woman presented with severe back pain in August 2015 and was found to have anaemia, hypercalcaemia, and renal impairment requiring immediate haemodialysis with a serum creatinine of $1,620 \mu \mathrm{mol} / \mathrm{L}$. Serum protein electrophoresis identified an IgD monoclonal protein of $1.2 \mathrm{~g} / \mathrm{L}$, whilst the serum-free light chain ratio (SFLCr) was abnormal with lambda 146 and kappa 13 (ratio 0.095). Magnetic resonance imaging showed widespread lyt- ic bone disease, and bone marrow (BM) examination revealed an infiltration of $80 \%$ plasma cells, confirming the diagnosis of MM. Renal ultrasound demonstrated normal sized kidneys, consistent with an acute kidney injury (renal biopsy not performed). She was treated with cyclophosphamide, bortezomib, and dexamethasone (8 cycles). A BM examination performed after $6 \mathrm{cy}$ cles showed $15 \%$ of plasma cells. Despite this improvement, she remained DD and proceeded to a stem cell harvest followed by melphalan $140 \mathrm{mg} / \mathrm{m}^{2}$ and ASCT, without major toxicity. Three months postASCT, the SFLCr was normal, serum protein electrophoresis did not show any IgD paraprotein, and BM plasma cells were $<5 \%$. As she remained DD, maintenance therapy was not received. In June 2017 (14 months post-ASCT), her renal function had improved to the extent that she became DI. Unfortunately, she relapsed in April 2018 and has commenced combination lenalidomide, bortezomib, and dexamethasone (RVD) but continues to be DI.

Here, we present the case of a young woman with IgD MM complicated by DD renal failure who became DI 14 months post-ASCT. To our knowledge, this is the first report of a patient with IgD MM achieving DI following ASCT. In MM, patients who remain DD fare particularly poorly, thus achieving DI should be a key goal of management in such cases [3]. Whilst DI can be achieved in $25-50 \%$ of de novo MM cases requiring dialysis at presentation with bortezomib-based therapy, the prospect of achieving DI after ASCT is much less predictable with rates between 5 and $20 \%$ reported in series with small patient numbers. El Fakih et al. [4] found that only 3 of 24 patients became DI at 1,3, and 32 months postASCT, whilst Glavey et al. [5] found that only 1 of 15 patients achieved DI in another series. In summary, here we described the case of a young woman with IgD MM and DD renal failure who despite this achieved DI 14 months after ASCT, further supporting the data presented by Kang et al. [1].

\section{Statement of Ethics}

The patient fully consents to the publication of this letter. There are no other ethical issues relating to this case to disclose.

\section{Disclosure Statement}

The authors have no conflicts of interest to declare.

\section{KARGER}

(c) 2018 S. Karger AG, Basel
Dr. John Quinn

Department of Haematology, Beaumont Hospital

Beaumont Road

Dublin 9 (Ireland)

E-Mail johnquinn@beaumont.ie 


\section{References}

1 Kang J, Hong JY, Yoon DH, Kim S, Lee KM, Park JS, et al. Efficacy and Survival Outcome Associated with the Use of Novel Agents and Autologous Stem Cell Transplantation in Cases of Immunoglobulin D Multiple Myeloma in Korea. Acta Haematol. 2018;139(3): 185-92.
2 Morris C, Drake M, Apperley J, Iacobelli S, van Biezen A, Bjorkstrand B, et al.; Myeloma Subcommittee of Chronic Leukaemia Working Party of EBMT. Efficacy and outcome of autologous transplantation in rare myelomas. Haematologica. 2010 Dec;95(12):2126-33.

3 Evison F, Sangha J, Yadav P, Aung YS, Sharif A, Pinney JA, et al. A population-based study of the impact of dialysis on mortality in multiple myeloma. Br J Haematol. 2018 Feb; 180(4):588-91.
4 El Fakih R, Fox P, Popat U, Nieto Y, Shah N, Parmar S, et al. Autologous Hematopoietic Stem Cell Transplantation in Dialysis-Dependent Myeloma Patients. Clin Lymphoma Myeloma Leuk. 2015 Aug;15(8):472-6.

5 Glavey SV, Gertz MA, Dispenzieri A, Kumar $\mathrm{S}$, Buadi F, Lacy M, et al. Long-term outcome of patients with multiple [corrected] myeloma-related advanced renal failure following auto-SCT. Bone Marrow Transplant. 2013 Nov;48(12):1543-7. 